\title{
Random UV-C mutagenesis of Scheffersomyces (formerly Pichia) stipitis NRRL Y-7124 to improve anaerobic growth on lignocellulosic sugars
}

\author{
Stephen R. Hughes - William R. Gibbons • Sookie S. Bang • Rebecca Pinkelman • Kenneth M. Bischoff • \\ Patricia J. Slininger · Nasib Qureshi · Cletus P. Kurtzman · Siqing Liu • Badal C. Saha · John S. Jackson • \\ Michael A. Cotta $\cdot$ Joseph O. Rich $\cdot$ Jeremy E. Javers
}

Received: 1 May 2011 / Accepted: 16 June 2011 / Published online: 12 July 2011

(C) The Author(s) 2011. This article is published with open access at Springerlink.com

\begin{abstract}
Scheffersomyces (formerly Pichia) stipitis NRRL Y-7124 was mutagenized using UV-C irradiation to produce yeast strains for anaerobic conversion of lignocellulosic sugars to ethanol. UV-C irradiation potentially produces large numbers of random mutations broadly and uniformly over the whole genome to generate unique strains. Wild-type cultures of S. stipitis NRRL Y-7124 were subjected to UV-C (234 $\mathrm{nm})$ irradiation targeted at approximately $40 \%$ cell survival. When surviving cells were selected in sufficient numbers via automated plating strategies and cultured anaerobically on xylose medium for 5 months at $28^{\circ} \mathrm{C}$, five novel mutagenized $S$. stipitis strains were obtained. Variable number tandem repeat analysis revealed that mutations had occurred in the genome, which may have produced genes that allowed the anaerobic utili-
\end{abstract}

Mention of trade names or commercial products in this article is solely for the purpose of providing specific information and does not imply recommendation or endorsement by the United States Department of Agriculture.

S. R. Hughes $(\bowtie) \cdot$ K. M. Bischoff · S. Liu · J. S. Jackson ·

J. O. Rich

Renewable Product Technology (RPT) Research Unit,

National Center for Agricultural Utilization Research (NCAUR),

Agricultural Research Service (ARS), United States Department

of Agriculture (USDA), 1815 North University Street, Peoria,

IL 61604, USA

e-mail: Stephen.Hughes@ars.usda.gov

W. R. Gibbons

Department of Biology and Microbiology, South Dakota State University, West Hall 104,

PO Box 2207B, Brookings, SD 57007, USA

\section{S. S. Bang $\cdot$ R. Pinkelman}

Department of Chemical and Biological Engineering,

South Dakota School of Mines and Technology,

501 East Saint Joseph Street, Rapid City, SD 57701-3995, USA zation of xylose. The mutagenized strains were capable of growing anaerobically on xylose/glucose substrate with higher ethanol production during 250 - to 500 -h growth than a Saccharomyces cerevisiae yeast strain that is the standard for industrial fuel ethanol production. The $S$. stipitis strains resulting from this intense multigene mutagenesis strategy have potential application in industrial fuel ethanol production from lignocellulosic hydrolysates.

Keywords Pichia stipitis [Scheffersomyces stipitis] · Cellulosic fuel ethanol · Anaerobic xylose fermentation . Yeast UV mutagenesis

\section{Introduction}

Over $90 \%$ of ethanol biofuel produced in the USA is made from corn starch using Saccharomyces strains to ferment the glucose obtained by hydrolysis of the starch. The

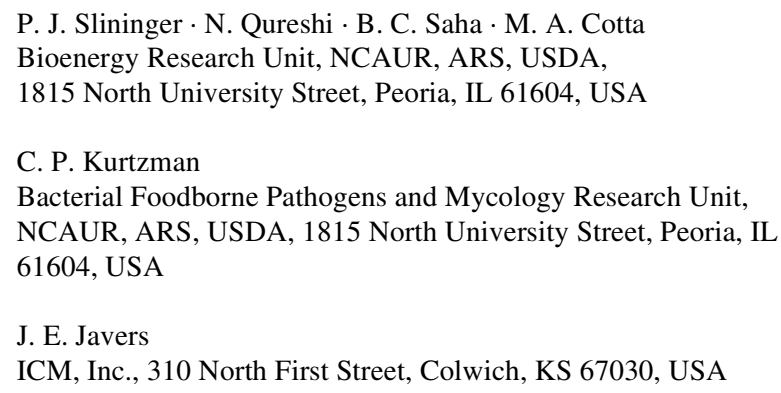


United States Environmental Protection Agency has revised the Renewable Fuel Standard (RFS) program as required by the Energy Independence and Security Act of 2007 (EISA). The final rule (RFS2) increases the volume requirements for total renewable fuel to 20.5 billion gallons and for cellulosic biofuel to 3.0 billion gallons by 2015 [43]. To meet these mandates, it will be necessary to use cellulosic biomass, an abundant and renewable carbon source [34], as a feedstock. However, the microbial strains used to ferment the glucose released by hydrolysis of starch are not capable of fermenting the more diverse mixture of sugars released by hydrolysis of lignocellulosic biomass [22]. In general, plant cell-wall lignocellulose contains, in decreasing order, mainly glucose, xylose, arabinose, and galactose. Saccharomyces strains are capable of fermenting the hexose sugars, glucose, and galactose; however, they do not naturally ferment the pentose sugars, xylose or arabinose [22]. Production of ethanol anaerobically from glucose by Saccharomyces strains is the standard to which microbes being developed to produce ethanol from biomass are compared $[1,2,20,26]$.

To efficiently convert lignocellulosic biomass to ethanol, it will be necessary to produce a yeast strain capable of utilizing both pentoses and hexoses. The well-studied yeast Scheffersomyces (formerly Pichia) stipitis [25] has the potential to be used more effectively for biomass conversion into ethanol than Saccharomyces strains because it can naturally ferment both pentose and hexose sugars [1, 20, 22, 36, 38, 39] under microaerophilic conditions. The strain produces up to $47 \mathrm{~g} / \mathrm{L}$ ethanol on xylose-containing medium under conditions of limited aeration [10] and gives ethanol yields up to $0.41 \mathrm{~g} / \mathrm{g}$ on wheat straw hydrolysate [32]. However, $S$. stipitis has a slower sugar consumption rate than Saccharomyces and requires oxygen for both growth and maximal ethanol production [1], although oxygen limitation induces fermentative activity [24, 33]. Because microaerophilic conditions are difficult to maintain uniformly in large-scale industrial fuel ethanol operations, enhancing the capability of this yeast to produce ethanol anaerobically could increase its value in industrial processes.

Here, we describe five novel $S$. stipitis strains that were obtained by UV-C irradiation of wild-type (WT) S. stipitis NRRL Y-7124 cultures, followed by 5-month anaerobic growth on xylose at $28^{\circ} \mathrm{C}$. UV-C irradiation is a standard technique [11, 19] for inducing mutations in yeast. The S. stipitis WT strain was not recovered from the plates after this treatment. The UV-C-mutagenized strains were able to grow anaerobically on xylose/glucose medium with higher ethanol production than a Saccharomyces cerevisiae yeast strain under comparable fermentation conditions. Comparison is made to $S$. cerevisiae because it is the strain currently used for industrial fuel ethanol production. The mutagenized strains were identified by DNA fingerprinting to be unique strains closely related to WT $S$. stipitis. These mutagenized strains have potential application in the largescale industrial conversion of lignocellulosic sugars to fuel ethanol.

\section{Materials and methods}

Mutagenization of $S$. (formerly Pichia) stipitis NRRL $\mathrm{Y}-7124$

\section{Preparation of strains 14 and 22}

Duplicate 2-L Fernbach flasks were prepared by inoculating each flask, containing $1 \mathrm{~L}$ of YM medium $[3 \mathrm{~g} / \mathrm{L}$ yeast extract and $3 \mathrm{~g} / \mathrm{L}$ malt extract, $5 \mathrm{~g} / \mathrm{L}$ peptone (BectonDickinson, Sparks, MD), $10 \mathrm{~g} / \mathrm{L}$ dextrose (Sigma, St. Louis, $\mathrm{MO})$ ], with $20 \mathrm{~mL}$ of a 2-day $\mathrm{YM} 28^{\circ} \mathrm{C}$ culture of WT S. stipitis NRRL Y-7124 [USDA, ARS, NCAUR (formerly Northern Regional Research Laboratory) Culture Collection] from a $100-\mathrm{mL}$ flask, and then incubating both flasks at $28^{\circ} \mathrm{C}$ for 2 days with shaking at $100 \mathrm{rpm}$. Before irradiation, a sample of the log phase culture was taken from the Fernbach flask to obtain an estimate of the number of cells using a Reichert Neubauer/Bright-Line Hemacytometer (American Optical Corp, Buffalo, NY). The culture from each flask was divided into two Beckman 500-mL spin bottles and pelleted in a Beckman Avanti J20 centrifuge (Beckman) at $20^{\circ} \mathrm{C}$ for $20 \mathrm{~min}$ at $2,056 \times g$. Cell pellets were washed and resuspended in $50 \mathrm{~mL}$ of sterile water. A 25-mL aliquot was taken from each resuspension and placed into a Marsh RR-0014 deep trough plate with baffled bottom (Marsh Biomedical Products, Rochester, NY). The plates were placed $14 \mathrm{~cm}$ below a source of UV-C radiation [234 nm; UVP, LLC Light Table (inverted), Upland, CA) and irradiated for $1 \mathrm{~min}$.

From each trough plate and using an automated protocol on a robotic workcell, we spread $600-\mu \mathrm{L}$ aliquots onto $128 \times 96-\mathrm{mm}$ Omni Tray plates (Thermo Fisher Scientific, Waltham, MA) containing (per liter) $2 \%$ xylose complete minimal medium plus all amino acids ( $1.4 \mathrm{~g}$ yeast synthetic drop-out medium supplement; $0.06 \mathrm{~g}$ L-leucine; $0.04 \mathrm{~g}$ L-tryptophan; $0.02 \mathrm{~g}$ L-histidine; $0.02 \mathrm{~g}$ uracil; $20 \mathrm{~g}$ D-xylose; Sigma-Aldrich); $15 \mathrm{~g}$ Bacto-Agar (Thermo Fisher Scientific); $6.7 \mathrm{~g}$ yeast nitrogen base without amino acids (Sigma-Aldrich); $5 \mathrm{~g}$ ammonium sulfate. The spread plates were wrapped in Saran wrap, sealed with Parafilm, and placed into a Mitsubishi anaerobic chamber (Mitsubishi Gas Chemical America, New York, NY) containing the AnaeroPack dry chemical system (Sigma Fluka, Buchs, Switzerland) at $28^{\circ} \mathrm{C}$ for 5 months to select for strains which, unlike the WT strain, could survive anaerobically on xylose for an extended period of time. 
Two large mounded colonies on plates 14 and 22 were the only visible signs of growth above the background lawn when the spread plates were unwrapped. Sterile pipette tips were touched to the tops of these mounds and inoculated onto plates containing rich YM or YPD (10 g/L yeast extract, $20 \mathrm{~g} / \mathrm{L}$ Bacto-Peptone, $20 \mathrm{~g} / \mathrm{L}$ D-glucose, $20 \mathrm{~g} / \mathrm{L}$ Bacto-Agar; Thermo Fisher Scientific) or $2 \%$ xylose complete minimal medium plus all amino acids and incubated at $28^{\circ} \mathrm{C}$ for 2 weeks anaerobically to check that these isolates were still capable of growth on glucose and to eliminate background. Five colonies were picked from the re-spread anaerobic xylose plates onto plates containing YM, YPD, or xylose complete minimal medium plus all amino acids and incubated aerobically at $28^{\circ} \mathrm{C}$ for 3 days to verify growth capability on xylose was still present and to provide starter cultures for the second round of irradiation. Two 100-mL flasks were inoculated with the cultures from the YM plates and incubated at $28^{\circ} \mathrm{C}$ for 3 days to prepare samples for more intensive irradiation.

\section{Preparation of strains WT-1-11, WT-2-1, 14-2-6, 22-1-1, and 22-1-12}

Eight 2-L Fernbach flasks were prepared by adding $1 \mathrm{~L}$ of YM medium to each flask. Four of these flasks were inoculated with WT strain S. stipitis NRRL Y-7124, two flasks were inoculated with strain 14 , and two flasks were inoculated with strain 22 , using $50-\mathrm{mL}$ aliquots from the respective $100-\mathrm{mL}$ flasks. Following the same procedures as described above, the Fernbach flasks were incubated, the cultures were centrifuged, and each of the cell pellets was washed and resuspended. A 25-mL aliquot was taken from each resuspension and placed into a Marsh RR-0014 deep trough plate with baffled bottom (Marsh Biomedical Products). The plates were placed $14 \mathrm{~cm}$ below a source of $\mathrm{UV}-\mathrm{C}$ radiation and irradiated at $234 \mathrm{~nm}$ for $4 \mathrm{~h}$. Before irradiation, a $10-\mu \mathrm{L}$ sample was taken from the trough plate, diluted $10^{-5}$, and read in the hemacytometer to determine the total initial number of cells. Samples were taken every hour during irradiation, diluted, and plated to determine the number of surviving cells. Stirring was conducted every hour to make sure all cells were equally exposed to the radiation. The liquid depth in the trough plates was not greater than $3 \mathrm{~mm}$, and plates were centered under the light source.

Spread plates were prepared on the robotic workcell as described above and placed into a Mitsubishi anaerobic chamber at $28^{\circ} \mathrm{C}$ for 5 months. One sample from each of the 42 surviving colonies on the anaerobic xylose plates was manually spread onto a plate containing rich YM, YPD, or xylose medium (one sample per plate) and incubated at $28^{\circ} \mathrm{C}$ aerobically to check that these strains were still capable of growth on glucose and xylose and to obtain single isolates. After 3 days of aerobic growth on xylose, the colonies on five of the plates were considerably larger than those on any of the other plates, so these five samples, designated WT-1-11, WT-2-1, 14-2-6, 22-1-1, and 22-1-12, were selected for further characterization and evaluation. The colonies were spread on YPD plates and incubated aerobically at $28^{\circ} \mathrm{C}$ for 3 days; the cells were then examined by scanning electron microscopy (SEM).

\section{SEM analysis}

Yeast cells from the plate were suspended in saline $(0.85 \%$ $\mathrm{NaCl}$ ) and centrifuged to remove residual medium. Following a modified procedure of Bang and Pazirandeh [7], the cell pellet was suspended and fixed in $2.5 \%$ glutaraldehyde prepared in $100 \mathrm{mM}$ cacodylate buffer, $\mathrm{pH} 7.2$, for $1 \mathrm{~h}$ on ice. To remove any remaining glutaraldehyde, the cells were rinsed with the buffer twice and then with distilled water once, allowing several minutes for each step. The cells were dehydrated in successive gradations of ethanol (50, 70, 80 and 100\%; 15 min each treatment), mounted on the aluminum stub, and placed in the desiccator to dry overnight or until needed. The samples were subjected to SEM and analysis (Zeiss Supra 40 VP; Carl Zeiss, Jena, Germany) [7].

Fermentation in 250-mL Erlenmeyer flasks

The fermentation performance of the five mutagenized S. stipitis yeast strains (WT-1-11, WT-2-1, 14-2-6, 22-1-1, and 22-1-12) were evaluated for glucose, xylose, and cellobiose using $100 \mathrm{~mL}$ of $50 \mathrm{~g} / \mathrm{L}$ sugar solutions with $5 \mathrm{~g} / \mathrm{L}$ yeast extract placed into 250-mL Erlenmeyer flasks closed with a rubber stopper equipped with a 21-gauge hypodermic needle and a filter for gas exchange. After autoclaving and cooling, each flask was inoculated with $1 \mathrm{~mL}$ of the respective $S$. stipitis strain (inoculum grown for $24 \mathrm{~h}$ at $35^{\circ} \mathrm{C}$ in glucose medium). The flasks were incubated at $35^{\circ} \mathrm{C}$ and $250 \mathrm{rpm}$ for $96 \mathrm{~h}$ (aerobic). Samples were removed at $0,3,6,9,12,24,36,48,72,96 \mathrm{~h}$. Glucose, xylose, cellobiose, and ethanol were analyzed by high-performance liquid chromatography (HPLC).

\section{Fermentation in the DASGIP fedbatch-pro system}

Fermentations were performed in a fedbatch-pro fermentation system (DASGIP BioTools, Shrewsbury, MA) maintained at $30^{\circ} \mathrm{C}$ with stirring $(150 \mathrm{rpm})$; oxygen was provided in the headspace for aerobic conditions, and the headspace and reactor were purged with nitrogen for anaerobic conditions. Liquid precultures were inoculated with colonies of yeast and incubated for 2 days at $30^{\circ} \mathrm{C}$ with shaking at $100 \mathrm{rpm}$. The density of the preculture was 
adjusted to an absorbance equivalent to 4.0 at $660 \mathrm{~nm}$, and $25 \mathrm{~mL}$ was added to $150 \mathrm{~mL}$ of medium in a 400-mL DASGIP culture vessel. Ethanol production was measured from xylose medium (YPX) consisting of $10 \mathrm{~g} / \mathrm{L}$ yeast extract, $20 \mathrm{~g} / \mathrm{L}$ Bacto-Peptone, and $20 \mathrm{~g} / \mathrm{L}$ xylose (Thermo Fisher Scientific) and from glucose plus xylose medium (YPD +YPX), consisting of $10 \mathrm{~g} / \mathrm{L}$ yeast extract, $20 \mathrm{~g} / \mathrm{L}$ BactoPeptone, $20 \mathrm{~g} / \mathrm{L}$ glucose, and $20 \mathrm{~g} / \mathrm{L}$ xylose.

Ethanol, glucose, and xylose analysis

Ethanol, xylose, and glucose concentrations were determined by HPLC using a 300-mm Aminex HPX-87H column (Bio-Rad, Hercules, CA) on an HP 1100 Series HPLC system equipped with a refractive index detector (Agilent Technologies, Santa Clara, CA). Samples $(10 \mu \mathrm{L})$ were injected onto a heated column $\left(65^{\circ} \mathrm{C}\right)$ and eluted at a rate of $0.6 \mathrm{~mL} / \mathrm{min}$ using $5 \mathrm{mM} \mathrm{H}_{2} \mathrm{SO}_{4}$ as mobile phase [35].

\section{DNA fingerprinting}

Variable nucleotide tandem repeat (VNTR) PCR analysis was performed to detect differences in genomic DNA sequences between mutagenized S. stipitis strains WT-111, WT-2-1, 14-2-6, 22-1-1, and 22-1-12 compared to the WT strains $S$. stipitis NRRL Y-7124 and Saccharomyces cerevisiae NRRL Y-2034 (USDA, ARS Culture Collection) using as both the forward and reverse PCR primer the 28-bp repeating unit of the highly polymorphic VNTR sequences present in the $3^{\prime}$ flanking region of the HRAS gene: 5'-AGGGGACGCCACACTCGCCCTTCTCTCC-3' [30].

Genomic DNA was isolated from cells in a 2-day culture ( $1 \mathrm{~g}$ wet weight). Cells were frozen in liquid nitrogen, broken up with a mortar and pestle, scraped into a $15-\mathrm{mL}$ conical tube, and the DNA isolated using the Qiagen DNeasy Plant Genomic kit (Qiagen, Valencia, CA) according to manufacturer's directions. The concentration of DNA obtained was $0.5 \mathrm{mg} / \mathrm{mL}$ determined spectrophotometrically (Beckman DU 800; Beckman) using absorbances at 260 and $280 \mathrm{~nm}$.

The PCR mixture contained $4 \mu \mathrm{L}$ DNA $(0.5 \mathrm{mg} / \mathrm{mL})$, $34 \mu \mathrm{L} \mathrm{H} \mathrm{H}_{2} \mathrm{O}, 10 \mu \mathrm{L} 5 \times$ Phusion HF Buffer, $1 \mu \mathrm{L} 10 \mathrm{mM}$ dNTPs, $0.5 \mu \mathrm{L}(1 \mathrm{mg} / \mathrm{mL})$ VNTR oligonucleotide, and $0.5 \mu \mathrm{L}$ Phusion Enzyme (Finnzymes Phusion High-Fidelity PCR kit; New England Biolabs, Ipswich, MA). The PCR reaction was prepared in a Bio-Rad hard-shell 96-well PCR plate on ice and was carried out in a PTC-225 Tetrad Thermal Cycler (Bio-Rad) using the following conditions: hold at $96^{\circ} \mathrm{C}$ for $5 \mathrm{~min}, 30$ cycles of $96^{\circ} \mathrm{C}$ for $1 \mathrm{~min}, 65^{\circ} \mathrm{C}$ for $1 \mathrm{~min}$, and $72^{\circ} \mathrm{C}$ for $1 \mathrm{~min}$, followed by $72^{\circ} \mathrm{C}$ for $7 \mathrm{~min}$ and a $4^{\circ} \mathrm{C}$ hold. The procedure amplified the genomic sequence between two VNTR sequences to determine alterations in the microsatellite or minisatellite regions in the genome caused by UV-C mutagenization. The amplified DNA was analyzed by gel electrophoresis on $1 \%(\mathrm{w} / \mathrm{v})$ agarose gels stained with ethidium bromide.

\section{Results and discussion}

Number of cells irradiated

The number of cells that would be needed to maximize the mutagenization of the S. stipitis genome was estimated to be approximately $9.0 \times 10^{6}$ based on the number of genes in the S. stipitis genome (about 5,841) and the average length of $S$. stipitis gene transcripts (1,500 nucleotides) [20]. The sample of the log phase culture taken from the Fernbach flasks prior to preparation for irradiation gave an estimate of $5.0 \times 10^{7}$ cells $/ \mathrm{mL}$ in the Reichert Neubauer hemacytometer.

An automated process is essential to analyze the number of samples needed [13-18]. The automated protocol on the robotic workcell for picking and spreading the irradiated cultures was developed for rapid sterile processing of six $128 \mathrm{~mm} \times 96-\mathrm{mm}$ Omni tray plates per run. Up to 270 plates can be stacked on the workcell for continuous processing, and the stacks can be readily re-filled as needed. The SoftLinx software moved the plates from several passive and active stackers to the liquid handler in a scheduled fashion where they were spotted with xylose medium and

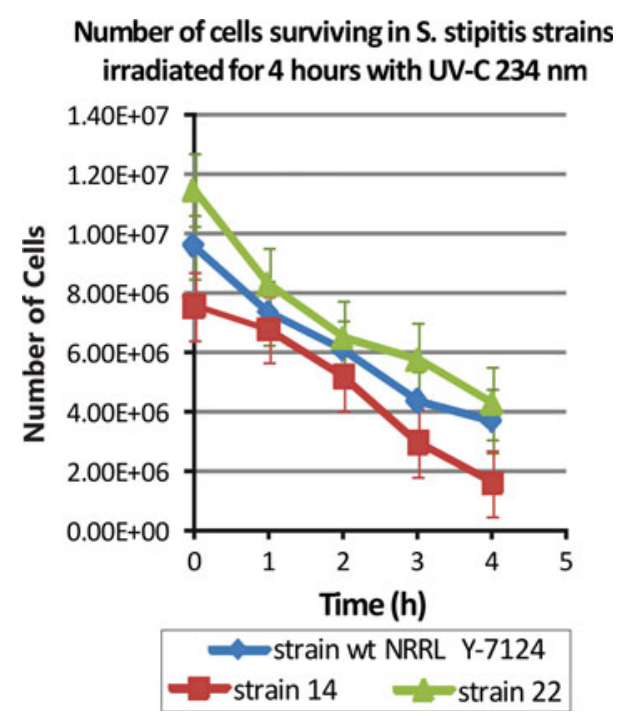

Fig. 1 Number of surviving cells in Sheffersomyces (Pichia) stipitis strains irradiated for $4 \mathrm{~h}$ with UV-C $234 \mathrm{~nm}$ determined hourly by plating $10 \mu \mathrm{L}$ of a $1: 10^{-5}$ dilution of sample from the trough plate. Each point is the average of two determinations. Wild-type (WT) S. stipitis NRRL Y-7124 strain was not previously irradiated. Strains 14 and 22 were isolates recovered after previous irradiation of the WT strain for 1 min followed by anaerobic incubation for 5 months 
then with irradiated culture from the Marsh deep trough plates on the deck. The plates with the irradiated samples were collected in sets of six and placed in anaerobic chambers.

Strains with improved anaerobic growth on xylose from 1-min UV-C irradiation (strains 14 and 22)

The plates obtained after a 1-min irradiation followed by 5-month anaerobic incubation on xylose medium showed considerable background growth, but two colonies appeared as mounds above the background lawn. Samples of these colonies were incubated anaerobically and then aerobically on both xylose and glucose media. The two mutagenized strains, 14 and 22, demonstrated growth aerobically as well as anaerobically on both substrates. Both aerobic and anaerobic growth capabilities are important for the optimum performance of an industrial yeast strain.
Strains with improved anaerobic growth on xylose $\mathrm{f}$ rom 4-h UV-C irradiation (14-2-6, 22-1-1, 22-1-12, WT-1-11, and WT-2-1)

Initially, a typical 1-min irradiation time was used, but the resulting plates showed considerable background growth so it was decided to use a longer irradiation time. The progress of the second irradiation was monitored by plating a sample from the trough plates and determining the number of surviving cells at hourly intervals after the initiation of irradiation of mutagenized S. stipitis strains 14 and 22 and the WT S. stipitis strain, with a target survival of about $40 \%$. The results are presented in Fig. 1. Strain 14 went from $7.4 \times 10^{6}$ cells initially to $2.0 \times 10^{6}$ cells at $4 \mathrm{~h}(27 \%$ survival), and strain 22 went from $1.1 \times 10^{7}$ cells initially to $4.4 \times 10^{6}$ cells $(39 \%$ survival). The WT strain went from $9.0 \times 10^{6}$ cells initially to $4.0 \times 10^{6}$ cells ( $44 \%$ survival). The average percentage survival after $4 \mathrm{~h}$ was $37 \%$. With the longer irradiation time, very little background growth
Fig. 2 Scanning electron micrographs of mutagenized S. (Pichia) stipitis strains WT-111, WT-2-1, 14-2-6, 22-1-1, and 22-1-12 compared to the WT strain S. stipitis NRRL Y-7124. Scale bar $2 \mu \mathrm{m}$ (bottom micrograph of each set) and $0.5 \mu \mathrm{m}$ (top micrograph of each set). In top micrographs, darker area is interior of cell; lighter region is exterior

Scanning electron micrographs of mutagenized S. stipitis strains
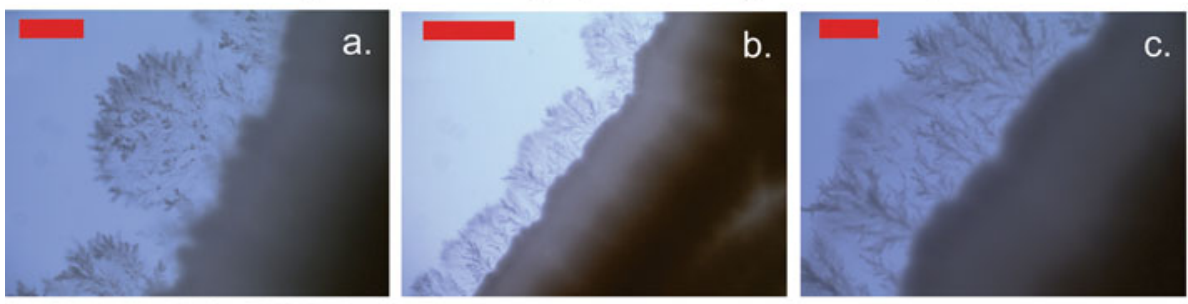

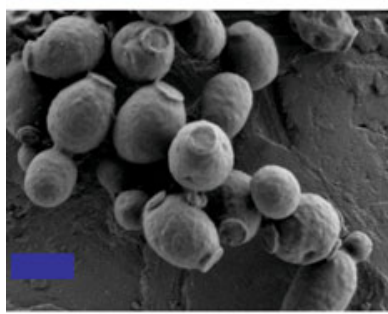

WT
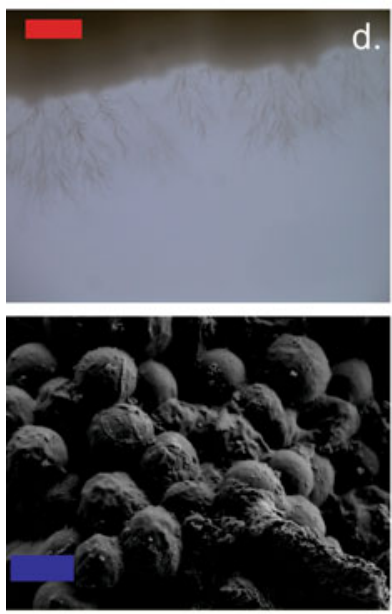

$14-2-6$

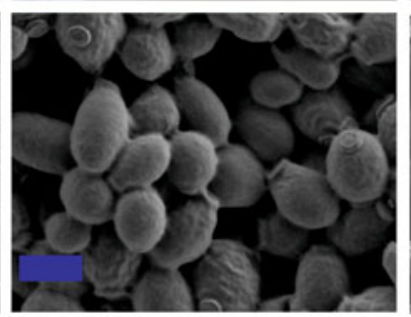

WT-1-11
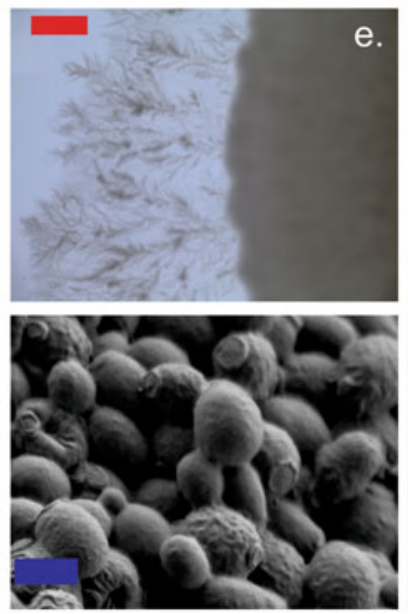

22-1-1

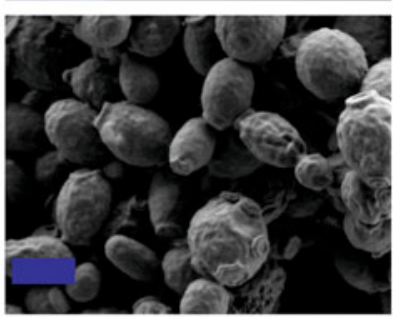

WT-2-1
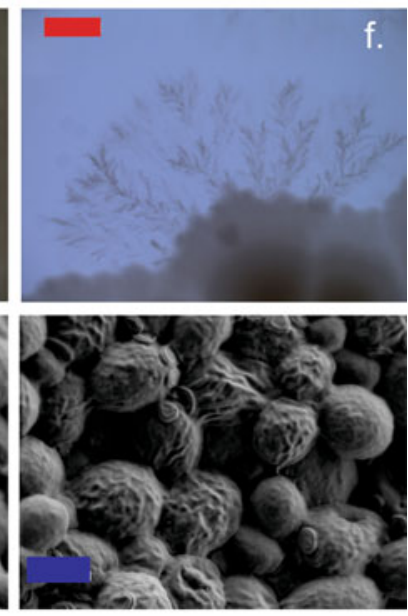

22-1-12 
was seen after 5 months of anaerobic growth on xylose plates so the surviving colonies were easier to isolate. Of the 42 surviving colonies, the five that grew best aerobically on xylose, WT-1-11, WT-2-1, 14-2-6, 22-1-1, and 22-1-12, were then incubated aerobically on glucose plates for analysis using SEM.

Differences in morphology observed in SEM analysis of strains 14-2-6, 22-1-1, 22-1-12, WT-1-11, and WT-2-1

The SEM results indicate that the five mutagenized S. stipitis strains which grew on xylose under anaerobic conditions are unique strains because their morphological features are different from each other and from that of the wild-type S. stipitis strain. The scanning electron micrograph of the wild-type $S$. stipitis NRRL Y-7124 shows that the cells are urn-shaped, from 2 to $3 \mu \mathrm{m}$ long, with bud scars at opposite ends of the cell (Fig. 2a, bottom) and are uniform in size, similar to the morphology observed by Jeffries et al. [20]. The cells of the WT strain also match the description given in Suh et al. [41] of globose- or subglobose-shaped cells with dimensions $2.2-4.5 \times 2.3-6.0 \mu \mathrm{m}$. It can be seen from the micrographs that although the general shape of the cells in the mutagenized strains is the same as that in the WT strain, the sizes of the cells are not uniform (Fig. 2b-f, bottom), with cells both smaller and larger than those in the WT strain appearing on the micrograph. The surfaces of the cells of the mutagenized strains were observed to have numerous bulges and ridges and to be much more irregular than the surface of the WT strain. At a finer resolution, the surfaces of the cells in the mutagenized strains differed considerably in width, regularity, and density from the WT strain and from each other (Fig. 2a-f, top).

\section{Differences in strains detected using VNTR PCR from genomic DNA}

Similarly, the resulting PCR products using a VNTR primer are indicative of changes to the DNA sequences in the genome of the mutagenized S. stipitis strains and also demonstrate that the strains are different from each other and from the wild-type $S$. stipitis strain. A high degree of polymorphism is often present with respect to the number of tandemly repeated units of a nucleotide sequence at a particular locus on the genome of an organism. These differences result in differences in PCR products amplified using the VNTR sequence as PCR primer and can be used to distinguish differences in the genome $[6,23,37]$. The VNTR PCR procedure amplified the genomic sequence containing the highly polymorphic VNTR sequences and indicates that alterations in these regions in the genome were induced by UV-C irradiation.

The DNA fingerprints for mutagenized S. stipitis strains WT-1-11, WT-2-1, 14-2-6, 22-1-1, and 22-1-12 compared to WT strains S. stipitis NRRL Y-7124 and Saccharomyces cerevisiae NRRL Y-2034 are presented in Fig. 3. New banding patterns generating a distinct fingerprint for each of the mutagenized strains that grew anaerobically on

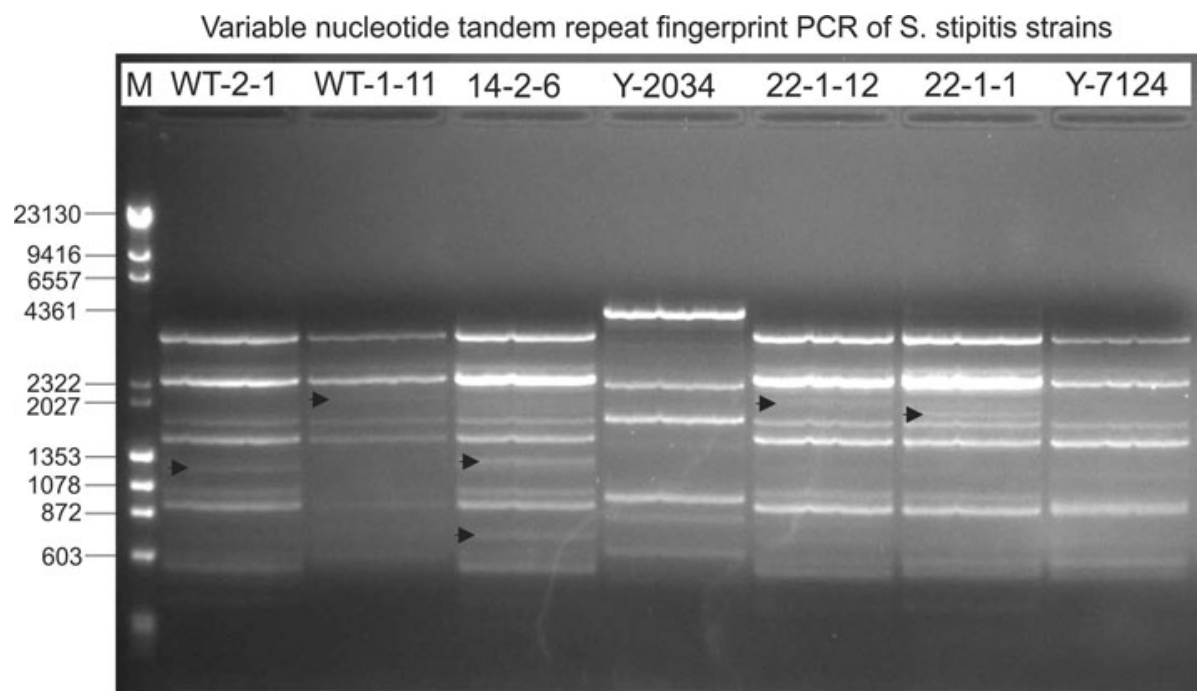

Fig. 3 Variable nucleotide tandem repeat (VNTR) fingerprint of the changes to the genomic DNA of mutagenized S. (Pichia) stipitis strains WT-2-1, WT-1-11, 14-2-6, 22-1-12, and 22-1-1 compared to Saccharomyces cerevisiae NRRL Y-2034 and the wild-type (WT) strain, S. stipitis NRRL Y-7124. Resulting PCR products were obtained using the VNTR primer-generated fragments and are indicative of changes to the genomes of the mutagenized strains and analyzed on a $1 \%(\mathrm{w} / \mathrm{v})$ agarose gel. Bionexus DNA base-pair markers (Lane $M$ ) are identified by length on the left of the figure. Bands present in mutagenized strains but not present in WT S. stipitis NRRL Y-7124 are indicated by arrows. Gel was run at $80 \mathrm{~V}$ on a Bio-Rad Power Pac 3000 system, and a high-resolution digital image file was generated with an AlphaImager 3400 gel imaging system using a trans-UV light (Alpha Innotech Corp, San Leandro, CA) 
Table 1 Fermentation results in 250-mL flask culture

\begin{tabular}{|c|c|c|c|c|c|}
\hline Strain $^{\mathrm{a}}$ & Ethanol $(\mathrm{g} / \mathrm{L})$ & $\begin{array}{l}\text { Ethanol yield } \\
\text { (\% theoretical) }\end{array}$ & $\begin{array}{l}\text { Ethanol productivity } \\
(\mathrm{g} / \mathrm{L} / \mathrm{h})\end{array}$ & $\begin{array}{l}\text { Residual } \\
\text { sugar }(g / L)\end{array}$ & $\begin{array}{l}\text { Fermentation } \\
\text { efficiency }(\%)\end{array}$ \\
\hline \multicolumn{6}{|c|}{ Glucose fermentation results at $48 \mathrm{~h}$} \\
\hline $14-2-6$ & 17.88 & 70.12 & 0.373 & 4.11 & 91.8 \\
\hline WT-1-11 & 16.97 & 66.55 & 0.354 & 6.68 & 86.6 \\
\hline WT-2-1 & 17.21 & 67.49 & 0.359 & 4.81 & 90.4 \\
\hline $22-1-1$ & 16.51 & 64.75 & 0.344 & 6.07 & 87.9 \\
\hline $22-1-12$ & 18.39 & 72.12 & 0.383 & 3.39 & 93.2 \\
\hline \multicolumn{6}{|c|}{ Cellobiose fermentation results at $48 \mathrm{~h}$} \\
\hline $14-2-6$ & 0.71 & 2.78 & 0.015 & 41.48 & 17.0 \\
\hline WT-1-11 & 0.70 & 2.75 & 0.015 & 40.91 & 18.2 \\
\hline WT-2-1 & 0.87 & 3.14 & 0.071 & 39.5 & 21.0 \\
\hline $22-1-1$ & 0.75 & 2.94 & 0.061 & 38.44 & 23.1 \\
\hline $22-1-12$ & 0.61 & 2.39 & 0.050 & 42.34 & 15.3 \\
\hline \multicolumn{6}{|c|}{ Xylose fermentation results at $96 \mathrm{~h}$} \\
\hline $14-2-6$ & 3.26 & 12.78 & 0.034 & 34.54 & 30.9 \\
\hline WT-1-11 & 1.62 & 7.53 & 0.020 & 37.47 & 25.1 \\
\hline WT-2-1 & 2.36 & 9.26 & 0.025 & 36.75 & 26.5 \\
\hline $22-1-1$ & 2.94 & 11.53 & 0.031 & 35.83 & 28.3 \\
\hline $22-1-12$ & 2.99 & 11.73 & 0.031 & 34.98 & 30.0 \\
\hline
\end{tabular}

Ethanol levels, ethanol yields (\% theoretical), ethanol productivities, residual sugar levels, and fermentation efficiencies of mutagenized Sheffersomyces stipitis strains WT-1-11, WT-2-1, 14-2-6, 22-1-1, and 22-1-12 in 250-mL flasks in liquid culture using either glucose, cellobiose, or xylose as substrate. Initial concentrations of all sugar carbon sources were $50 \mathrm{~g} / \mathrm{L}$. Theoretical yield for glucose is $50 \mathrm{~g} / \mathrm{L}[(2 \times 46) / 180]=25.6 \mathrm{~g} / \mathrm{L}$; for cellobiose, $50 \mathrm{~g} / \mathrm{L}[(4 \times 46) / 342]=26.9 \mathrm{~g} / \mathrm{L}$; for xylose, $50 \mathrm{~g} / \mathrm{L}[(10 \times 46) /(6 \times 150)]=25.6 \mathrm{~g} / \mathrm{L}$. Fermentation efficiency $=(50 \mathrm{~g} / \mathrm{L}-$ residual sugar $\mathrm{g} / \mathrm{L}) \times 100 / 50 \mathrm{~g} / \mathrm{L}$

${ }^{\text {a }}$ WT-1-11 and WT-2-1 strains were produced by $4 \mathrm{~h}$ of 234-nm irradiation of wild-type S. stipitis NRRL Y-7124; the 14-2-6 strain was produced by $4 \mathrm{~h}$ of 234-nm irradiation of strain 14 previously irradiated with $234 \mathrm{~nm}$ for $1 \mathrm{~min}$; strains 22-1-1 and 22-1-12 strains were produced by 4 h of 234-nm irradiation of strain 22 previously irradiated with $234 \mathrm{~nm}$ for $1 \mathrm{~min}$

xylose are shown on the agarose gel. The arrows point out bands that are present in the fingerprints of the five mutagenized strains but not in the fingerprint of the S. stipitis NRRL Y-7124 WT strain. Strains WT-2-1 and 14-2-6 both have new bands at approximately $1,200 \mathrm{bp}$ that are not present in the other mutagenized strains; however, strain 14-2-6 has a new band at approximately 700 bp that does not appear in strain WT-2-1 or in any of the other strains. Strains WT-1-11 and 22-1-12 both have one new band at $2,027 \mathrm{bp}$ that is not seen in WT strain Y-7124. The exact nature of all mutations that have occurred in these strains will need to be investigated by comparative DNA sequencing.

Ethanol production and substrate use by mutagenized strains in $250-\mathrm{mL}$ flasks (aerobic conditions)

Under aerobic conditions, all strains used glucose efficiently; however, at $48 \mathrm{~h}$, strains 14-2-6 and 22-1-12 achieved the highest ethanol levels, productivities, and fermentation efficiencies, while having the lowest residual sugar levels (Table 1, top). When cellobiose was provided as the carbon source, all strains performed poorly, but in these trials at $48 \mathrm{~h}$, strains WT-2-1 and 22-1-1 performed slightly better than the other strains (Table 1 , middle). The results using xylose as the carbon source showed that at $96 \mathrm{~h}$, the strains performing best were 14-2-6 and 22-1-12 (Table 1, bottom). However, compared to the results with glucose at $48 \mathrm{~h}$ (about $18 \mathrm{~g}$ ethanol/L), these strains produced only about $3 \mathrm{~g}$ ethanol/L on xylose after $96 \mathrm{~h}$, which is about $12 \%$ of the theoretical yield $(25.6 \mathrm{~g} / \mathrm{L}$ for xylose). However, the fermentation efficiency was about $30 \%$, indicating that less than half the consumed xylose was converted to ethanol.

Ethanol production and substrate use by mutagenized strains in fermentor

\section{Under microaerophilic conditions}

Although anaerobic utilization of xylose is the desired characteristic in the mutagenized strains, the comparison to the WT strain was made under microaerophilic conditions because the WT strain requires microaeration for ethanol 
Sugar utilization and ethanol production from S. stipitis strains under microaerophilic conditions a Total Sugars Consumed

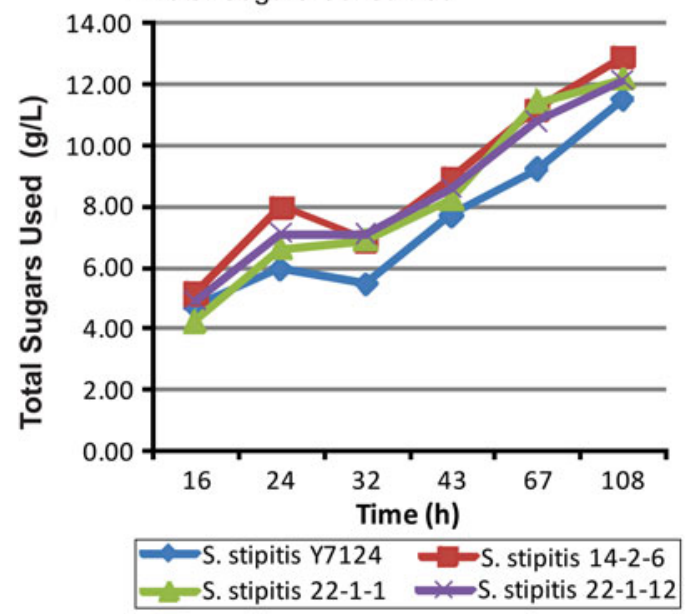

b Ethanol Produced / Cell Density

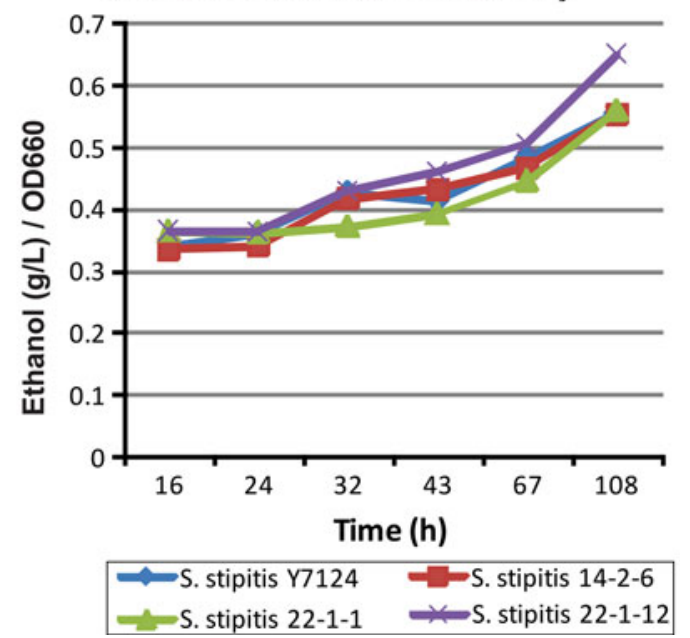

Fig. 4 Sugar utilization (a) and ethanol production/cell density (b) of mutagenized strains 14-2-6, 22-1-1, and 22-1-12 compared to the WT strain, S. stipitis NRRL Y-7124, in liquid culture initially containing $20 \mathrm{~g}$ xylose $+20 \mathrm{~g}$ glucose in a 400 -mL DASGIP reactor under microaerophilic conditions

production from xylose $[1,20,36]$. Total sugar consumption and ethanol production after $108 \mathrm{~h}$ by mutagenized strains compared to the WT strain, S. stipitis NRRL Y-7124, in liquid culture containing xylose and glucose under microaerophilic conditions (oxygen in headspace) in a DASGIP reactor are presented in Fig. $4 \mathrm{a}$. The mutagenized strains showed essentially the same pattern of total sugar consumption as the WT strain under the microaerophilic conditions required by the WT strain.

After $500 \mathrm{~h}$ (data not shown), the mutagenized strains produced $9.0-9.7 \mathrm{~g} / \mathrm{L}$ ethanol, which was close to the amount produced by the WT strain under the same conditions. The yields for the mutagenized S. stipitis strains were $0.23-0.24 \mathrm{~g}$ ethanol/g glucose + xylose, compared with
$0.27 \mathrm{~g}$ ethanol $/ \mathrm{g}$ glucose + xylose for the WT S. stipitis strain. When ethanol production was normalized for cell density, mutagenized strain 22-1-12 was found to have produced a higher level of ethanol than the WT strain and the mutagenized strains 14-2-6 and 22-1-1 over a period of 108 h (Fig. 4b).

In comparison, Agbogbo et al. [2] obtained yields of $0.38-0.41 \mathrm{~g}$ ethanol/g glucose + xylose on synthetic glucose/xylose mixtures under microaerophilic conditions for 120 h using S. stipitis CBS6054 and a higher total initial concentration of sugars ( $30 \mathrm{~g}$ glucose $+30 \mathrm{~g}$ xylose) and a higher initial cell density (OD about 10) than those used in our study. In comparison, our results were obtained with S. stipitis NRRL Y-7124 using $20 \mathrm{~g}$ glucose $+20 \mathrm{~g}$ xylose and an initial cell density of $\mathrm{OD}=1$. However, WT S. stipitis NRRL Y-7124 as a control run under the same conditions as those used in our study showed that the mutants, under the microaerophilic conditions required by the wild type, produced ethanol yields close to that of the wild type. Agbogbo and Wenger [5] found that hemicellulose hydrolysate was fermented to $15 \mathrm{~g} / \mathrm{L}$ ethanol in $72 \mathrm{~h}$ by S. stipitis CBS 6054, at yields of $0.37-0.44 \mathrm{~g}$ ethanol/g glucose + xylose. The ethanol yields with $S$. stipitis varied depending on the initial cell concentration [3], pretreatment chemicals [4], nitrogen source [39], culture nutrition, and physiology [40]. Depending on the lignocellulosic hydrolysate tested, researchers have obtained ethanol yields ranging from 0.32 to $0.48 \mathrm{~g}$ ethanol/g substrate using S. stipitis $[8,9,12,31,32,42]$.

\section{Under anaerobic conditions}

Ethanol production under strictly anaerobic conditions (media and reactor headspace purged with nitrogen prior to inoculation) by mutagenized strains WT-1-11, 22-1-12, and 14-2-6 compared to S. cerevisiae NRRL Y-2034 with glucose plus xylose medium over a period of about $500 \mathrm{~h}$ is shown in Fig. 5. It was not possible to evaluate $S$. stipitis NRRL Y-7124 because it does not grow under strictly anaerobic conditions. S. cerevisiae NRRL Y-2034 [27] reached a maximum ethanol production of about $9.5 \mathrm{~g} / \mathrm{L}$ $(0.24 \mathrm{~g}$ ethanol $/ \mathrm{g}$ glucose + xylose $)$ within $12 \mathrm{~h}$, with no further increase (some decrease in level was seen, possibly from evaporation) after glucose was depleted because this strain cannot utilize xylose. The mutagenized strains reached a level of ethanol production equal to the maximum level achieved by $S$. cerevisiae NRRL Y-2034 from 80 (strain 22-1-12) to $180 \mathrm{~h}$ (strain WT-1-11). Ethanol production continued to increase for the mutagenized strains, which were capable of using xylose as a substrate, reaching $13 \mathrm{~g} / \mathrm{L}$ at $490 \mathrm{~h}$ (strains 22-1-12 and WT-1-11). The yield at that point was approximately $0.33 \mathrm{~g}$ ethanol/g glucose + xylose for these mutagenized S. stipitis strains. 
Fig. 5 Ethanol production by mutagenized strains 22-1-12, WT-1-11, and 14-2-6 in liquid culture initially containing $20 \mathrm{~g}$ xylose +20 g glucose compared to the WT strain Saccharomyces cerevisiae NRRL Y-2034 under anaerobic conditions in the DASGIP reactor
Anaerobic ethanol production in 400-mL DASGIP reactor

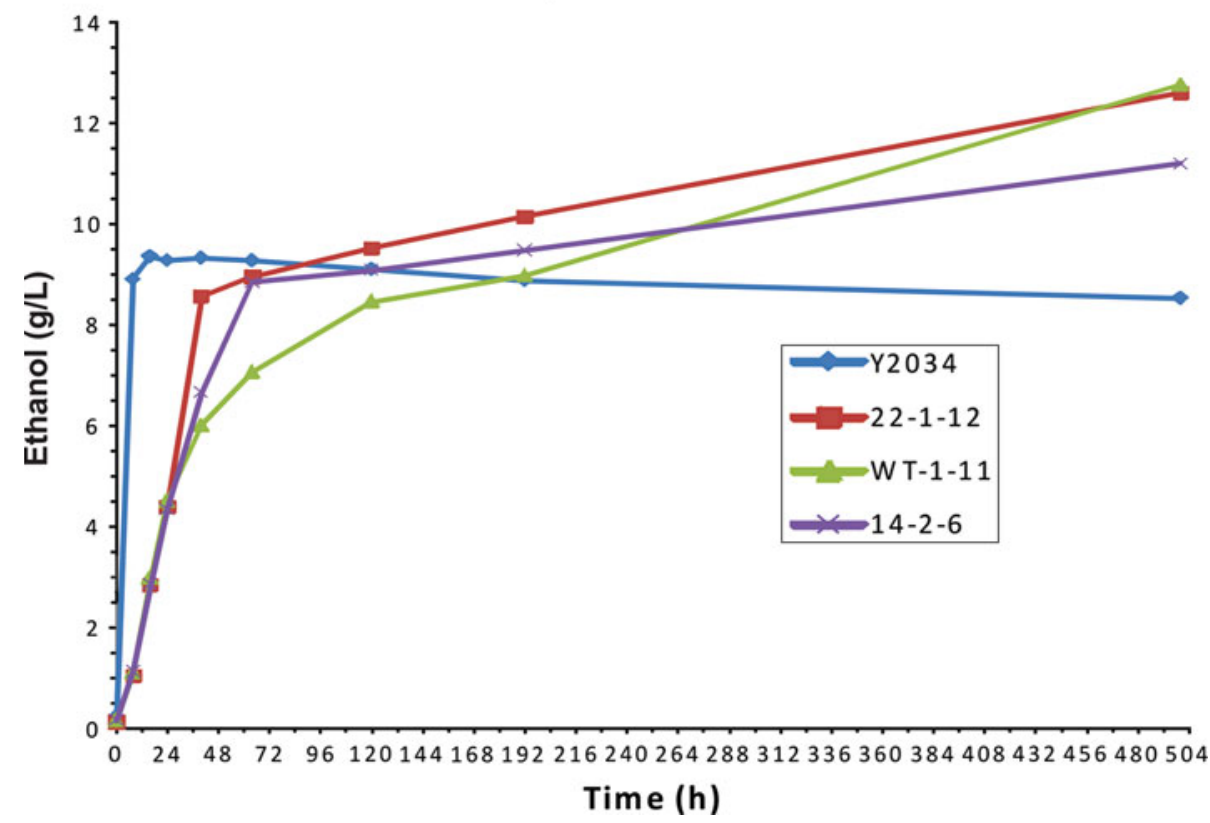

One notable result that we obtained was that the mutagenized S. stipitis strains which produced the most ethanol under anaerobic conditions, 22-1-12 and 14-2-6, were also those that showed the greatest amount of disruption to their cell membrane surfaces, as observed in the scanning electron micrographs. The cell surfaces in these strains were found to be much more uneven and cratered than the surfaces of the S. stipitis wild type or the other mutagenized S. stipitis strains, suggesting that there might be alterations in the cell membrane such as those which occur in xylosefermenting yeasts in response to temperature and ethanol stress [21]. One of the factors limiting anaerobic growth on xylose by $S$. stipitis is transport across the cell membrane. Factors that affect membrane fluidity, such as the ratio of cell lipids and proteins, also affect temperature and ethanol tolerance [21]. Ethanol stress increases both unsaturated fatty acids and ergosterol composition of the yeast cell membrane [21]. Ethanol-tolerant yeast strains usually contain a plasma membrane ATPase activity that is resistant to ethanol inhibition. It has also been shown that glucosegrown yeast cells have a higher ATPase activity than xylose-grown cells and that glucose-grown cells are more ethanol tolerant than xylose-grown cells [28, 29]. It is possible that changes in the cell surfaces of the mutagenized $S$. stipitis strains that grew anaerobically on xylose reflect alterations in the cell membrane.

The changes in S. stipitis resulting from the UV-C irradiation used in this study have produced mutant organisms that merit further investigation since they possess traits that are desirable in the large-scale industrial conversion of lignocellulosic sugars to fuel ethanol.
Acknowledgments We thank Karen Hughes for critical reading and formatting of the manuscript. We acknowledge the assistance of Nathane Orwig in obtaining the PCR primer.

Open Access This article is distributed under the terms of the Creative Commons Attribution Noncommercial License which permits any noncommercial use, distribution, and reproduction in any medium, provided the original author(s) and source are credited.

\section{References}

1. Agbogbo FK, Coward-Kelly G (2008) Cellulosic ethanol production using the naturally occurring xylose-fermenting yeast, Pichia stipitis. Biotechnol Lett 30(9):1515-1524

2. Agbogbo FK, Coward-Kelly G, Torry-Smith M, Wenger KS (2006) Fermentation of glucose/xylose mixtures using Pichia stipitis. Process Biochem 41(11):2333-2336. doi:101016/j.procbio. 2006.05.004

3. Agbogbo FK, Coward-Kelly G, Torry-Smith M, Wenger KS, Jeffries TW (2007) The effect of initial cell concentration on xylose fermentation by Pichia stipitis. Appl Biochem Biotechnol 140(1-12): 653-662

4. Agbogbo FK, Wenger KS (2006) Effect of pretreatment chemicals on xylose fermentation by Pichia stipitis. Biotechnol Lett 28(24):2065-2069

5. Agbogbo FK, Wenger KS (2007) Production of ethanol from corn stover hemicellulose hydrolyzate using Pichia stipitis. J Ind Microbiol Biotechnol 34(11):723-727

6. Alcoba-Flórez J, del Pilar Arévalo-Morales M, Pérez-Roth E, Laich F, Rivero-Pérez B, Méndez-Álvarez S (2007) Yeast molecular identification and typing. In: Méndez-Vilas A (ed) Communicating current research and educational topics and trends in applied microbiology. Formatex Research Center, Extremadura, pp 535-546

7. Bang SS, Pazirandeh M (1999) Physical properties and heavy metal uptake of encapsulated Escherichia coli expressing a metal binding gene (NCP). J Microencapsul 16(4):489-499 
8. Cho DH, Shin S-J, Bae Y, Park C, Kim YH (2010) Enhanced ethanol production from deacetylated yellow poplar acid hydrolysate by Pichia stipitis. Bioresour Technol 101(13):4947-4951. doi:10.1016/j.biortech.2009.11.014

9. Díaz MJ, Ruiz E, Romero I, Cara C, Moya M, Castro E (2009) Inhibition of Pichia stipitis fermentation of hydrolysates from olive tree cuttings. World J Microbiol Biotechnol 25(5):891-899. doi:10.1007/s11274-009-9966-9

10. du Preez JC, van Driessel B, Prior BA (1989) Ethanol tolerance of Pichia stipitis and Candida shehatae strains in fed-batch cultures at controlled low dissolved oxygen levels. Appl Microbiol Biotechnol 30(1):53-58

11. Hashimoto S, Ogura M, Aritomi K, Hisashi H, Nishizawa Y, Akada R (2005) Isolation of auxotrophic mutants of diploid industrial yeast strains after UV mutagenesis. Appl Environ Microbiol 71(1):312-319. doi:10.1128/AEM.71.1.312-319.2005

12. Huang C-F, Lin T-H, Guo G-L, Hwang W-S (2009) Enhanced ethanol production by fermentation of rice straw hydrolysate without detoxification using a newly adapted strain of Pichia stipitis. Bioresour Technol 100(17):3914-3920. doi:10.1016/j.biortech.2009. 02.064

13. Hughes SR, Dowd PF, Hector RE, Panavas T, Sterner DE, Qureshi N, Bischoff KM, Bang SS, Mertens JA, Johnson ET, Li X-L, Jackson JS Jr, Caughey RJ, Riedmuller SB, Bartolett S, Liu S, Rich JO, Farrelly PJ, Butt TR, LaBaer J, Cotta MA (2008) Lycotoxin-1 insecticidal peptide optimized by amino acid scanning mutagenesis and expressed as a coproduct in an ethanologenic Saccharomyces cerevisiae strain. J Pept Sci 14(9):1039-1050

14. Hughes SR, Dowd PF, Hector RE, Riedmuller SB, Bartolett S, Mertens JA, Qureshi N, Liu S, Bischoff KM, Li X-L, Jackson JS Jr, Sterner D, Panavas T, Rich JO, Farrelly PJ, Butt TR, Cotta MA (2007) Cost-effective high-throughput fully automated construction of a multiplex library of mutagenized open reading frames for an insecticidal peptide using a plasmid-based functional proteomic robotic workcell with improved vacuum system. J Assoc Lab Autom 12(4):202-212

15. Hughes SR, Hector RE, Rich JO, Qureshi N, Bischoff KM, Dien BS, Saha BC, Liu S, Cox EJ, Jackson JS Jr, Sterner DE, Butt TR, LaBaer J, Cotta MA (2009) Automated yeast mating protocol using open reading frames from Saccharomyces cerevisiae genome to improve yeast strains for cellulosic ethanol production. J Assoc Lab Autom 14:190-199

16. Hughes SR, Rich JO, Bischoff KM, Hector RE, Qureshi N, Saha BC, Dien BS, Liu S, Jackson JS, Sterner DE, Butt TR, LaBaer J, Cotta MA (2009) Automated yeast transformation protocol to engineer Saccharomyces cerevisiae strains for improved cellulosic ethanol production with open reading frames that express proteins binding to xylose isomerase identified using a robotic two-hybrid screen. J Assoc Lab Autom 14:200-212

17. Hughes SR, Riedmuller SB, Mertens JA, Li X-L, Bischoff KM, Qureshi N, Cotta MA, Farrelly PJ (2006) High-throughput screening of cellulase $\mathrm{F}$ mutants from multiplexed plasmid sets using an automated plate assay on a functional proteomic robotic workcell. Proteome Sci 4:10

18. Hughes SR, Sterner DE, Bischoff KM, Hector RE, Dowd PF, Qureshi N, Bang S, Grynaviski N, Chakrabarty T, Johnson ET, Dien BS, Mertens JA, Caughey RJ, Liu S, Butt T, Labaer J, Cotta MA, Rich JO (2008) Three-plasmid SUMO yeast vector system for automated high-level functional expression of value-added co-products in a Saccharomyces cerevisiae strain engineered for xylose utilization. Plasmid 61(1):22-38

19. James AP, Kilbey BJ (1977) The timing of UV mutagenesis in yeast: a pedigree analysis of induced recessive mutation. Genetics $87: 237-248$

20. Jeffries TW, Grigoriev IV, Grimwood J, Laplaza JM, Aerts A, Salamov A, Schmutz J, Lindquist E, Dehal P, Shapiro H, Jin Y-S,
Passoth V, Richardson PM (2007) Genome sequence of the lignocelluloses-bioconverting and xylose-fermenting yeast Pichia stipitis. Nat Biotechnol 25(3):319-326. doi:10.1038/nbt1290

21. Jeffries TW, Jin Y-S (2000) Ethanol and thermotolerance in the bioconversion of xylose by yeasts. Adv Appl Microbiol 47:221268

22. Jeffries TW, Jin Y-S (2004) Metabolic engineering for improved fermentation of pentoses by yeasts. Appl Microbiol Biotechnol 63(5):495-509. doi:10.1007/s00253-003-1450-0

23. Kappe R, Fauser C, Okeke CN, Maiwald M (1996) Universal fungus-specific primer systems and group-specific hybridization oligonucleotides for 18S rDNA. Mycoses 39(1-2):25-30

24. Klinner U, Fluthgraf S, Freese S, Passoth V (2005) Aerobic induction of respire-fermentative growth by decreasing oxygen tensions in the respiratory yeast Pichia stipitis. Appl Microbiol Biotechnol 67(2):247-253

25. Kurtzman CP, Robnett CJ (2010) Systematics of methanol assimilating yeasts and neighboring taxa from multigene sequence analysis and the proposal of Peterozyma gen. nov., a new member of the Saccharomycetales. Fed Eur Microbiol Soc (FEMS). Yeast Res 10(3):353-361

26. Ligthelm ME, Prior BA, duPreez JC (1988) The oxygen requirements of yeasts for the fermentation of D-xylose and D-glucose to ethanol. Appl Microbiol Biotechnol 28:63-68

27. McGhee JE, St. Julian G, Detroy RW, Bothast RJ (1982) Ethanol production by immobilized Saccharomyces cerevisiae, Saccharomyces uvarum, and Zymomonas mobilis. Biotechnol Bioeng 25:1155-1163

28. Meyrial V, Delgenes JP, Romieu C, Moletta R, Gounot A-M (1995) Ethanol tolerance and activity of plasma membrane ATPase in $P i$ chia stipitis grown on D-xylose or on D-glucose. Enzyme Microb Tech 17(6):535-540. doi:10.1016/0141-0229(94)00065-Y

29. Meyrial V, Delgenes J-P, Romieu C, Moletta R, Gounot A-M (1995) In vivo ethanol-activation of the plasma membrane ATPase of Pichia stipitis: effect of the carbon source. J Biotechnol 42(2):109-116. doi:10.1016/0168-1656(95)00063-V

30. Nakamura Y, Koyama K, Matsushima M (1998) VNTR (variable number of tandem repeat) sequences as transcriptional, translational, or functional regulators. J Hum Genet 43:149-152

31. Nigam JN (2001) Development of xylose-fermenting yeast Pichia stipitis for ethanol production through adaptation on hardwood hemicellulose acid prehydrolysate. J Appl Microbiol 90(2):208-215

32. Nigam JN (2001) Ethanol production from wheat straw hemicellulose hydrolysate by Pichia stipitis. J Biotechnol 87(1):17-27

33. Passoth V, Cohn M, Schäfer B, Hahn-Hägerdal B, Klinner U (2003) Analysis of the hypoxia-induced ADH2 promoter of the respiratory yeast Pichia stipitis reveals a new mechanism for sensing oxygen limitation in yeast. Yeast 20(1):39-51

34. Perlack RD, Wright LL, Turhollow AF, Graham RL, Stokes BJ, Erbach DC (2005) Biomass as a feedstock for a bioenergy and bioproducts industry: the technical feasibility of a billion-ton annual supply: A joint study sponsored by U.S. Department of Energy and U.S. Department of Agriculture. U.S. Department of Energy and U.S. Department of Agriculture, Washington, D.C.

35. Qureshi N, Saha BC, Cotta MA (2007) Butanol production from wheat straw hydrolysate using Clostridium beijerinckii. Bioprocess Biosyst Eng 30:419-427

36. Rudolf A, Baudel H, Zacchi G, Hahn-Hägerdal B, Lidén G (2008) Simultaneous saccharification and fermentation of steam-pretreated bagasse using Saccharomyces cerevisiae TMB3400 and Pichia stipitis CBS6054. Biotechnol Bioeng 99(4):783-790

37. Shemer R, Weissman Z, Hashman N, Kornitzer D (2001) A highly polymorphic degenerate microsatellite for molecular strain typing of Candida krusei. Microbiology 147:2021-2028

38. Slininger PJ, Bothast RJ, Ladisch MR, Okos MR (1990) Optimum $\mathrm{pH}$ and temperature conditions for xylose fermentation by Pichia stipitis. Biotechnol Bioeng 35:727-731 
39. Slininger PJ, Dien BS, Gorsich SW, Liu Z (2006) Nitrogen source and mineral optimization enhance D-xylose conversion to ethanol by the yeast Pichia stipitis. Appl Microbiol Biotechnol 72(6): 1285-1296. doi:10.1007/s00253-006-0435-1

40. Slininger PJ, Gorsich SW, Liu Z (2009) Culture nutrition and physiology impact the inhibitor tolerance of the yeast Pichia stipitis NRRL Y-7124. Biotechnol Bioeng 102(3):788-790

41. Suh S-O, White MM, Nguyen NH, Blackwell M (2004) The status and characterization of Enteroramus dimorphus: a xylose-fer- menting yeast attached to the gut of beetles. Mycologia 96(4):756760

42. Telli-Okur M, Eken-Saraçoğlu N (2008) Fermentation of sunflower seed hull hydrolysate to ethanol by Pichia stipitis. Bioresour Technol 99(7):2162-2169. doi:10.1016/j.biortech.2007.05.036

43. United States Environmental Protection Agency (2010) EPA finalizes regulations for the National Renewable Fuel Standard program for 2010 and beyond. EPA-420-F-10-007. USEPA, Washington, D.C. 